\title{
PLANOS DE AÇÃO EDUCATIVA RELACIONADOS AO ACONSELHAMENTO MEDICAMENTOSO DE PACIENTES COM DIABETES MELLITUS TIPO 2 ATENDIDOS NA ATENÇÃO PRIMÁRIA
}

\author{
Lais P. Giovanini, Maria Helena M. Lima, Danilo D. Trevisan.
}

\begin{abstract}
Resumo
Este estudo teve como objetivos caracterizar o perfil medicamentoso de pacientes com DM2 atendidos na atenção primária e elaborar planos de ação educativa focalizado no aconselhamento medicamentoso dos principais medicamentos utilizados por estes pacientes. Trata-se de um estudo transversal conduzido em unidades de atenção primária. A prescrição médica do último mês foi solicitada ao paciente e, em seguida, registradas as seguintes informações: nome genérico do medicamento, dose e posologia (frequência/dia). O sistema Micromedex ® 2.0 foi utilizado para identificar e analisar os cuidados envolvendo as orientações clínicas a serem ofertadas aos pacientes. Participaram deste estudo 88 usuários com DM2. Identificou-se predomínio de mulheres com idade entre 42 e 75 anos com baixa renda e escolaridade. A maioria dos participantes fez uso de polifarmácia. As classes de medicamentos mais prescritas foram: antidiabéticos orais, hipolipemiantes e antiagregantes plaquetários. $O$ esclarecimento de eventos adversos, o modo de tomar os medicamentos, a associação ou não com alimentos e o uso concomitante de bebida alcoólica foram os planos de aconselhamento mais prevalentes. $O$ aconselhamento medicamentoso realizado por enfermeiros na atenção básica pode ser uma estratégia educativa voltada para promoção mais seguro do uso de medicamentos.
\end{abstract}

Palavras-chave: aconselhamento; diabetes mellitus tipo 2; enfermagem primária.

\section{Introdução}

O tratamento do diabetes mellitus tipo 2 (DM2) pode implicar numa sobrecarga para a vida do paciente e proporcionar diferentes necessidades de informações sobre o uso de medicamentos. $\mathrm{O}$ aconselhamento medicamentoso é uma parte central de segurança e está relacionado ao processo de informar e orientar pacientes para promoção do uso racional da terapêutica medicamentosa. Assim, os objetivos deste estudo foram caracterizar o perfil medicamentoso de pacientes com DM2 atendidos na atenção primária e elaborar planos de ação educativa focalizado no aconselhamento medicamentoso dos principais medicamentos utilizados por estes pacientes.

\section{Resultados e Discussão}

- Trata-se de um estudo transversal conduzido em duas unidades de atenção primária entre fevereiro e dezembro de 2016.

- A prescrição médica do último mês foi solicitada ao paciente e, em seguida, registradas as seguintes informações: nome genérico do medicamento, dose e posologia (frequência/dia). A identificação e análise dos cuidados envolvendo 0 aconselhamento medicamentoso foi realizada por meio do Micromedex (B) 2.0 .

- Participaram deste estudo 88 usuários com DM2. Identificou-se predomínio de mulheres $(70,8 \%)$ com média de idade de 61,4 anos (DP 8,3). A média de escolaridade foi de 5,9 anos (DP 4,5) e a renda familiar mensal foi de 2,9 salários mínimos (DP 1,9).

- A maioria dos participantes fez uso de polifarmácia $(67,1 \%)$. Os medicamentos mais prescritos, o modo de administração e as instruções clínicas são apresentados na tabela 1 .
Tabela 1. Orientações do aconselhamento medicamentoso

\begin{tabular}{ccc}
\hline $\begin{array}{c}\text { Medicamento } \\
(\%)\end{array}$ & Administração & Instruções clínicas \\
\hline $\begin{array}{ccc}\text { Metformina } \\
95,6 \%\end{array}$ & - Após refeições & Possíveis Eventos adversos: \\
& ou mastiga-los. & diarreia, dispepsia, flatulência, \\
& - Não administrar & náuseas/vômitos. \\
& Ontes e após 48 & Orientações: \\
& horas de exames & Relatar sinais / sintomas de \\
& radiológicos com & acidose láctica; manter \\
& contraste iodado. & prevenir a disfunção renal. \\
& Não ingerir bebida alcoólica. \\
\hline Sinvastatina & - Ingeridos à noite & Possíveis Eventos adversos: \\
$62,5 \%$ & e com o estômago & dores musculares, artralgia, \\
& vazio. & Orientações: \\
& & Relatar sintomas de miopatia ou \\
& & rabdomiólise. \\
\hline Ácido acetil & - Ingerir após as & Possíveis eventos adversos: \\
salicílico & refeições na & dispepsia, tontura, cefaleia. \\
$37,5 \%$ & mesma hora todos & Orientações: \\
& os dias & Relatar sinais e sintomas de \\
& qualquer tipo de sangramento e \\
& de úlcera gastrointestinal. Evitar \\
& mastigar & uso de outros anti-inflamatórios \\
& não esteroidais concomitante. \\
\hline
\end{tabular}

\section{Conclusões}

O aconselhamento medicamentoso pode ser uma estratégia educativa para aumentar o conhecimento dos usuários, melhorar a adesão ao tratamento e minimizar/prevenir eventos adversos. O enfermeiro deve levantar os principais problemas relacionados à terapêutica medicamentosa por meio da consulta de enfermagem e implementar intervenções educativas para o aconselhamento medicamentoso do paciente.

\section{Agradecimentos}

PIBIC - SAE - Bolsa IC (Quota 2017/2018) 